\title{
Xenobiotic-Metabolizing Enzymes in Skeletal Muscle of Children and Adolescents
}

\author{
Dora Molina-Ortiz ${ }^{1,2}$, José Francisco González-Zamora ${ }^{3}$, Rafael Camacho-Carranza ${ }^{4}$, \\ Ocarol Lopez-Acosta ${ }^{1}$, Oscar Colin-Martinez ${ }^{5}$, Adriana Miriam Domínguez-Ramírez $^{6}$, \\ Araceli Vences-Mejía ${ }^{*}$
}

${ }^{1}$ Laboratorio de Toxicología Genética, Instituto Nacional de Pediatría (INP), México City, México; ${ }^{2}$ Doctorado en Ciencias Biológicas y de la Salud, Universidad Autónoma Metropolitana (UAM), México City, México; ${ }^{3}$ Laboratorio de Cirugía Experimental, INP, México City, México; ${ }^{4}$ Instituto de Investigaciones Biomédicas, Universidad Nacional Autónoma de México, México City, México; ${ }^{5}$ Servicio de Ortopedia, INP, México City, México. ${ }^{6}$ Laboratorio de Farmacocinética y Farmacodinamia, UAMX, México City, México.

Email: ${ }^{*}$ aritaven@yahoo.com.mx

Received January $18^{\text {th }}, 2013$; revised March $2^{\text {nd }}, 2013$; accepted April $7^{\text {th }}, 2013$

Copyright (C) 2013 Dora Molina-Ortiz et al. This is an open access article distributed under the Creative Commons Attribution License, which permits unrestricted use, distribution, and reproduction in any medium, provided the original work is properly cited.

\begin{abstract}
Cytochrome P450 (CYP) enzymes metabolize endogenous compounds such as steroid hormones, fatty acids, and xenobiotics, including drugs and carcinogens. The skeletal muscle is highly exposed to circulating xenobiotics; nevertheless the knowledge on the expression of these enzymes not only in adult skeletal muscle but also in younger individuals has been very little. Therefore, the aim of the present study was to investigate the expression of CYP enzymes in healthy skeletal muscles of children and adolescents. This was investigated in a total of 18 biopsies taken from the quadriceps skeletal muscle of younger patients: 9 boys and 9 girls ( $\leq 18$ years) by using specific antibodies in immunoblots and by RT-PCR mRNA analysis. The mRNA transcripts for CYP1B1 and CYP2E1 were consistently detected in all samples, but in the immunoblot only was identified CYP1B1 protein in four samples. Regarding CYP1A1, CYP3A4 and CYP3A5 enzymes in skeletal muscle, there were found in some samples in both techniques, although with significant inter-individual variations. Finally CYP2W1 only was detected in one sample belonging to the youngest patient. These data show that a range of CYP enzymes are expressed in the skeletal muscle of children and adolescents, suggesting that the metabolism of several xenobiotic chemicals to which humans are exposed takes place in muscle cells. Moreover, since the potential participation of muscles is a fact in pharmacokinetics of many therapeutic drugs, expression of CYPs in skeletal muscle may play an important role in drug-dependent toxicity.
\end{abstract}

Keywords: Cytochrome P450; Skeletal Muscle; Children; Adolescents

\section{Introduction}

The role of skeletal muscle as a site of extrahepatic xenobiotic metabolism has not been sufficiently addressed, despite accounting for around $45 \%$ of total body weight and it is characterized by high metabolic rate and blood flow. This later characteristic makes it highly exposed to circulating drugs with $13 \%-98 \%$ binding ability [1]. In addition, it is known that skeletal muscle may sequester some therapeutic drugs [2]. Reports have shown that drugs could easily enter and leave the tissues, and that muscle and fat constitute an important drug storage sites particularly following multiple dosing [3]. It has been

${ }^{*}$ Corresponding author. recognized that numerous drugs have been reported to possess myotoxic effects [4] such as weakness, tenderness, and rhabdomyolysis. These therapeutics drugs include neuromuscular-blocking agents, antihistamines, diuretics, antibiotics, chemotherapy drugs, and high-dose steroids [5]. Consequently, the expression profile of metabolizing enzymes in the muscle tissue may play a major role in drug myotoxicity.

It has been estimated that approximately $75 \%$ (threequarter) of drugs that are primarily cleared via metabolism are biotransformed by cytochrome P450 (CYP) enzymes. Thus is a multigene family of constitutively expressed and inducible enzymes involved in the oxidative metabolic activation and detoxification the many com- 
pounds [6]. Majority of CYP enzymes are mainly expressed in the liver. However, several CYPs contribute to drug metabolism in extrahepatic tissues as small intestine, colon, respiratory tract, or skin, which are organs directly in contact with xenobiotics $[7,8]$. Since the expression of the majority of the isoforms appears to be very low in extrahepatic tissues in comparison with the predominant expression in adult liver, the role of these enzymes in overall biotransformation and total body clearance is minor. Nevertheless, basal expression and up-regulation of extrahepatic CYP enzymes can significantly affect local disposition of xenobiotics or endogenous compounds in peripheral tissues and thus modify their pharmacological/toxicological effects or affect absorption of xenobiotics in the systemic circulation [9]. Until now, three main CYP families (1, 2, and 3), containing 23 isoforms, have been identified as being involved in xenobiotic metabolism. It is known that expression of these enzymes have to be regulated by physiological, pathological, genetic, and environmental factors [10]. Xenobiotics themselves play an important role as CYP inducers; enhancing CYP expression is indeed a common cellular mechanism leading to increased metabolism of foreign compounds. Thus, their induction mechanism is mostly transcriptional, resulting in elevated mRNA levels [11]. Indeed, typical CYP inducers, such as Phenobarbital, rifampicin, and 2,3,7,8-tetrachlorodibenzo-p-dioxin, activate nuclear receptors as constitutive androstane receptor (CAR), pregnane X receptor (PXR), and aryl hydrocarbon receptor (AhR) correspondingly, which bind to specific responsive elements in CYP2B, CYP3A, or CYP1 gene sequences, respectively. Extrahepatic CYP can contribute significantly to endogenous tissue function, drug biotransformation, and systemic exposure to foreign compounds [12]. Moreover there is a growing interest in the regulation of CYP enzymes in extrahepatic tissues for their importance in bio-activation of several inert compounds to reactive intermediates to form carcinogens or toxicants. These bioactive metabolites are often unstable and therefore are unlikely to be transported from the liver to other tissues. Therefore, the chemical toxicity found in extrahepatic tissues results from cellular metabolic activeties in situ in the tissues [13]. CYP-mediated drug metabolism can also lead to altered drug efficacies through the inactivation of an active drug or activation of a prodrug. Because most drugs have their targets in extrahepatic tissues, the extent and characteristics of target tissue drug metabolism may have a significant impact on effectiveness of treatment [14].

The expression profile of some CYPs has previously been investigated in human skeletal muscle of adults, but generally by analyzing a pooled from several normal muscles. However, little is known about the metabolic potential in skeletal muscle of younger individuals. The presence and activity of CYP enzymes in skeletal muscle in pediatric period may significantly affect the efficacy and safety of several drugs. Therefore, the aim of this study was to analyze expression patterns of CYP enzymes in skeletal muscle of children and adolescents.

\section{Materials and Methods}

\subsection{Samples Human Skeletal Muscle}

The study was performed with appropriate ethical approval according to the Declaration of Helsinki [15]. Parents and legal guardians of patients gave informed written consent and in adolescents also of the same patient. Eighteen biopsies from human quadriceps skeletal muscle were obtained from children and adolescents ( 9 boys and 9 girls) aged $0-17$ years participated undergoing orthopedic surgery or diagnostic procedures at National Institute of Pediatrics, Mexico City, Mexico. None of the subjects had known metabolic or malignant diseases nor were they taking medications that could significantly alter metabolism. In all cases, the tissues used for the purposes of this study were histologically benign based on examination of H\&E sections of tissues taken parallel.

\subsection{Tissues and Isolation of Total RNA and Protein}

All skeletal muscle specimens were immediately placed in RNAlater ${ }^{\mathrm{TM}}$ (Ambion, Austin, TX, USA) in the operating room and frozen in liquid nitrogen. The samples were subsequently stored at $-80^{\circ} \mathrm{C}$ until used. Total RNA and protein was isolated using Trizol reagent (Invitrogene, Gaithersburg, MD, USA).

\subsection{Immunoblot Analysis}

Primary antibody used for the detection of CYP1B1 was purchased from Millipore, Inc. (Bedford, MA). Polyclonal antibodies raised CYP1A1, CYP1A2, CYP2B6, CYP2E1, CYP2W1, CYP3A4 and CYP3A5 were purchased from Santa Cruz Biotechnology (Santa Cruz, CA). Supersomes were from cell lines/clones over-expressing human CYP1A1, CYP1A2, CYP2B6, CYP2E1, CYP3A4 and CYP3A5 were purchased from BD Biosciences (New Jersey, USA) while Supersomes for CYP1B1 were obtained from BD Gentest (Woburn, MA). These were used as internal standards for testing cross reactivity of antibodies. The proteins extracted from the Trizol fractions were quantified by Lowry method [16], using bovine serum albumin as a standard. Forty micrograms of protein were separated on a $10 \%$ polyacrylamide gel and electrophoretically transferred onto a polyvinylidene difluoride membrane. To ensure equal loading of samples, membranes were stained with Ponceau Red. In addition, some blots were probed for $\beta$-actin (Sigma, Munich, 
Germany) to ascertain identical protein loading of samples. Membranes were blocked in 5\% non-fat milk in Tris-buffered saline-Tween 20 (TBST, $0.01 \% \mathrm{v} / \mathrm{v}$ Tween 20) and probed with optimized dilutions of primary antibodies in TBS. Membranes were washed and treated with a secondary antibody (horseradish peroxidase conjugate). Protein bands were detected by enhanced chemiluminescent substrate using Immuno-Star HRP substrate kit (Bio$\mathrm{Rad})$.

\subsection{Reverse Transcription and Quantitative Polymerase Chain Reaction (qPCR)}

The integrity of total RNA isolated using Trizol reagent was evaluated by formaldehyde-agarose gel electrophoresis and confirmed by visualization of $18 \mathrm{~S}$ and $28 \mathrm{~S}$ rRNA bands. RNA concentrations were quantified using a NanoDrop Spectrophotometer (NanoDrop Technologies, Walmington, DE) at a wavelength of $260 \mathrm{~nm}$. The synthesis of complementary DNA (cDNA) was performed using $2 \mathrm{mg}$ of total RNA and TaqMan ${ }^{\circledR}$ reverse transcription reagents (Applied Biosystems): $1 \times$ TaqMan RT buffer, $\mathrm{MgCl}_{2}(5.5 \mathrm{mM})$, random hexamer $(2.5 \mu \mathrm{M})$, dNTP mix (dGTP, dCTP, dATP and dTTP, each one at a concentration of $500 \mu \mathrm{M})$, RNase inhibitor $(0.4 \mathrm{U} / \mu \mathrm{L})$, reverse transcriptase (MultiScribe, $1.25 \mathrm{U} / \mu \mathrm{L}$ ) and RNasefree water, in a final volume of $100 \mu \mathrm{L}$. The mixture was then incubated in thermal cycler at $25^{\circ} \mathrm{C}$ for $10 \mathrm{~min}$, at $48^{\circ} \mathrm{C}$ for $30 \mathrm{~min}$ and at $95^{\circ} \mathrm{C}$ for $5 \mathrm{~min}$. Each reaction was performed in triplicate and "no template" controls were included in each experiment. The concentration was determined by spectrophotometric analysis. cDNA samples were stored at $-20^{\circ} \mathrm{C}$ prior to use. Q-PCR for human messenger RNA (mRNA) levels was performed on ABI 7700 Sequence Detector (Applied Biosystems, CA). The primer and probe sets for each specific gene (Applied Biosystems, CA) were as follows: Hs00153120 (CYP1A1), Hs01070374 (CYP1A2), Hs00164383 (CYP1B1), Hs01020676 (CYP2B6), Hs01682803 (CYP2C9), Hs00559370 (CYP2E1), Hs00908623 (CYP2W1), Hs00430021 (CYP3A4), Hs01070905 (CYP3A5) and $4333762 \mathrm{~F}$ ( $\beta$-actin) as internal control.

\subsection{Analysis of Gene Expression}

The threshold was set at 0.3 for all genes. The threshold cycle $(\mathrm{Ct})$ value was determined using RQ1.2 software (Applied Biosystems). Ct values for target genes were normalized to $\mathrm{Ct}$ value of reference gene, creating $\Delta \mathrm{Ct}$ values $\left(\mathrm{Ct}_{\text {target gene }}-\mathrm{Ct}_{\beta \text {-actin }}\right)$. Inter-individual variations in gene expression were calculated using comparative threshold cycle method [17]. After $\Delta \mathrm{Ct}$ computation, alterations in gene expression were by comparing the samples with the sample used as a calibrator (patient No. 7 ), with a result of $\Delta \Delta \mathrm{Ct}$ values. Finally, relative gene expression was calculated using the formula $2^{-\Delta \Delta C T}$.

\section{Results}

\subsection{Patient Details for Study Participation}

Samples of quadriceps skeletal muscle $(n=18)$ were obtained from children and adolescents aged 0 - 17 years, with age range of 0.5 to 17 years (mean age 6.36) from male and female individuals (ratio 9:9) (Table 1). All skeletal muscle samples used for the expression analyses were deemed benign based on histopathological examination of H\&E sections of tissues taken parallel (Dates not shown).

\section{2. mRNA Expression of CYP Enzymes in Skeletal Muscle}

We initially investigated the expression of some CYP enzymes in human skeletal muscle using qPCR gene expression analyses of metabolizing enzymes (CYP1A1, CYP1A2, CYP1B1, CYP2E1, CYP2W1, CYP3A4, CYP3A5). Ranges of averaged threshold cycle (CT) values of amplified cDNA were examined in order to identify whether mRNA transcript levels for the genes examined were readily quantifiable. Levels of approximately 30 or below are readily detectable and quantifiable whereas levels $>35$, increasingly give rise to less robust analyses (Table 2).

Table 1. Details of study participants.

\begin{tabular}{cccc}
\hline Patient & Age (years) & Age group & Gender \\
\hline 1 & 0.5 & Children & \\
2 & 2 & Children & \\
3 & 3 & Children & \\
4 & 4 & Children & \\
5 & 6 & Children & Girls \\
6 & 9 & Children & \\
7 & 10 & Children & \\
8 & 11 & Children & \\
9 & 17 & Adolescent & \\
10 & 2 & Children & \\
11 & 6 & Children & \\
12 & 7 & Children & \\
13 & 8 & Children & Boys \\
14 & 9 & Children & \\
15 & 12 & Adolescent & \\
16 & 14 & Adolescent & \\
17 & 15 & Adolescent & \\
18 & 16 & Adolescent & \\
\hline
\end{tabular}

Age group: Children $\leq 12$, Adolescents 13 - 18 . 
Table 2. CT values for mRNA transcripts in the examined skeletal muscle tissues [Mean CT value (mean $\beta$-actin CT value)].

\begin{tabular}{|c|c|c|c|c|c|c|c|}
\hline GIRLS & & & & & & & \\
\hline Patient & CYP1A1 & CYP1A2 & CYP1B1 & CYP2E1 & CYP2W1 & CYP3A4 & CYP3A5 \\
\hline 1 & $35.5(27.22)$ & ND (28.82) & $28.84(26.89)$ & $33.76(25.24)$ & $36.43(26.3)$ & ND (30.87) & $37.28(26.99)$ \\
\hline 2 & $37.26(24.33)$ & ND (23.44) & $29.50(23.44)$ & $29.24(23.44)$ & ND (26.7) & $34.74(23.44)$ & $34.4(23.49)$ \\
\hline 3 & ND (28.97) & ND (29.46) & $32.38(29.46)$ & $35.23(29.46)$ & ND (29.46) & ND (29.46) & ND (29.46) \\
\hline 4 & $37.42(26.14)$ & ND (28.93) & $34.13(26.01)$ & 31.95 (28.93) & ND (28.93) & ND (28.93) & $37.33(26.24)$ \\
\hline 5 & ND (29.46) & ND (22.78) & $30.4(22.78)$ & $32.90(22.78)$ & ND (22.78) & 37.49 (22.78) & $36.63(22.78)$ \\
\hline 6 & ND (35.86) & ND (28.21) & $34.13(26.01)$ & $32.97(28.85)$ & ND (30.9) & ND (28.15) & ND (29.03) \\
\hline 7 & $34.57(19.43)$ & $38.6(29.02)$ & $29.49(28.16)$ & $31.63(34.54)$ & ND (31.69) & $36.47(28.16)$ & $36.98(32.47)$ \\
\hline 8 & $37.96(29.57)$ & $37.52(27.79)$ & $31.41(27.79)$ & $32.64(31.53)$ & ND (27.38) & $35.69(33.33)$ & $37.26(26.28)$ \\
\hline 9 & ND (25.7) & $37.90(23.21)$ & $28.43(23.21)$ & $31.52(23.21)$ & ND (23.21) & $37.39(23.21)$ & $38.33(23.21)$ \\
\hline \multicolumn{8}{|l|}{ BOYS } \\
\hline 1 & ND (27.76) & $37.3(26.14)$ & $32.92(25.56)$ & $36.06(27.76)$ & ND (23.15) & $37.73(26.14)$ & $37.18(26.14)$ \\
\hline 2 & $36.28(24.67)$ & ND (25.75) & $32.75(25.59)$ & $34.26(25.53)$ & ND (23.56) & ND (25.65) & ND (25.59) \\
\hline 3 & $36.56(23.09)$ & $32.41(22.58)$ & $30.65(21.82)$ & $25.95(24.12)$ & ND (23.15) & $36.33(24.35)$ & $27.77(23.27)$ \\
\hline 4 & ND (25.7) & ND (26.68) & $33.23(25.21)$ & $36.55(25.7)$ & ND (26.59) & $36.9(26.08)$ & $35.46(26.59)$ \\
\hline 5 & $36.55(27.86)$ & ND (27.98) & $32.66(27.95)$ & 33.68 (27.95) & ND (27.9) & $37.51(27.71)$ & 37.38 (27.5) \\
\hline 6 & $39.15(24.33)$ & ND (24.33) & $30.09(24.33)$ & $30.83(24.33)$ & ND (21.07) & ND (24.33) & ND (24.33) \\
\hline 7 & $38.96(23.92)$ & ND (24.19) & $35.67(31.25)$ & $33.55(24.05)$ & ND (24.05) & 37.7 (23.9) & $35.15(28.51)$ \\
\hline 8 & ND (31.14) & ND (35.19) & $34.38(28.98)$ & $35.13(31.11)$ & ND (31.11) & $36.61(33.04)$ & 36.99 (31.92) \\
\hline 9 & ND (31.96) & ND (27.97) & $29.51(27.97)$ & 31.75 (27.97) & ND (23.15) & $37.73(26.14)$ & ND (27.97) \\
\hline
\end{tabular}

ND: not detectable. This table presents the raw data required for the relative gene expression analysis shown in Table 3 . The mean CT values of each gene investigated and the mean CT value of $\beta$-actin (in brackets), is given for each patient. Gene expression analysis is performed by comparing $\beta$-actin values with those of the gene of interest, relative to one "control" patient known as the calibrator in order to determinate relative inter-patient differences. In this case patient 7 (girl of 10 years) was chosen as the control and is consequently assigned a gene expression value of 1 in subsequent analyses (see Table 3).

Quantifiable mRNA transcripts to CYP1A1 were detectable in 10 of the 18 samples while CYP1A2 was only only detectable in 5 of them. Also, CYP2E1 mRNA transcripts were detectable in all samples but levels below 35 of CT were observed in only 14 of the 18 samples. In contrast, the unique specimen where CYP2W $1 \mathrm{mRNA}$ transcripts were quantifiable belongs to a six-month old girl (patient 1). RNAm transcripts to CYP3A4 and CYP3A5 were detected in 12 samples but were below the limit of quantification (CT levels > 35) (Table 2).

Table 3 shows inter-individual variations in relative expression of the CYP genes tested. Marked differences in inter-individual expression of CYP genes were observed. CYP1A1 was highly expressed in skeletal muscle. Indeed, some individuals had high mRNA levels (10 of 18), whereas in others CYP1A1 was undetectable. The variation in CYP1A1 expression in positive samples was 107-fold difference between specimens. Only in five samples was CYP1A2 mRNA detected at low levels. We detected that both CYP1B1 and CYP2E1 genes were constitutively expressed at low mRNA levels, and had less variation than other CYPs. Relative gene expression of CYP3A4 and CYP3A5 showed wide variation of 0.011 to 61.82 and 0.001 to 1.0 mRNA amounts respec- 
Table 3. Relative gene expression in skeletal muscle by RT-PCR.

\begin{tabular}{|c|c|c|c|c|c|c|c|}
\hline GIRLS & & & & & & & \\
\hline Patient & CYP1A1 & CYP1A2 & CYP1B1 & CYP2E1 & CYP2W1 & CYP3A4 & CYP3A5 \\
\hline 1 & 116.16 & ND & 0.65 & 0.0004 & +++ & ND & 0.018 \\
\hline 2 & 4.62 & ND & 0.03 & 0.002 & ND & 0.12 & 0.012 \\
\hline 3 & ND & $\mathrm{ND}$ & 0.33 & 0.002 & ND & ND & ND \\
\hline 4 & 14.52 & ND & 0.009 & 0.016 & ND & ND & 0.01 \\
\hline 5 & ND & ND & 0.01 & 0.0001 & ND & 0.01 & 0.002 \\
\hline 6 & ND & ND & 0.009 & 0.007 & ND & ND & $\mathrm{ND}$ \\
\hline $7^{*}$ & 1 & 1 & 1 & 1 & ND & 1 & 1 \\
\hline 8 & 107.63 & 0.45 & 0.2 & 0.06 & ND & 61.82 & 0.011 \\
\hline 9 & ND & 0.01 & 0.06 & 0.0004 & ND & 0.017 & 0.001 \\
\hline \multicolumn{8}{|l|}{ BOYS } \\
\hline 1 & ND & 0.16 & 0.01 & 0.0004 & ND & 0.1 & 0.01 \\
\hline 2 & 11.55 & ND & 0.01 & 0.0003 & ND & ND & ND \\
\hline 3 & 3.18 & 0.42 & 0.006 & 0.03 & ND & 0.07 & 1 \\
\hline 4 & ND & ND & 0.01 & 0.0001 & ND & 0.17 & 0.04 \\
\hline 5 & 87.42 & ND & 0.09 & 0.002 & ND & 0.35 & 0.02 \\
\hline 6 & 1.24 & ND & 0.04 & 0.001 & ND & ND & ND \\
\hline 7 & 1.07 & ND & 0.11 & 0.0002 & ND & 0.02 & 0.22 \\
\hline 8 & ND & ND & 0.06 & 0.008 & ND & 26.72 & 0.67 \\
\hline 9 & ND & ND & 0.86 & 0.009 & ND & 23.1 & ND \\
\hline
\end{tabular}

ND: not detectable. For inter-individual variations between patients, the mRNA transcript levels derived from the patient number 7 was arbitrarily taken as the calibrator (*) as set to 1 . Quantitative gene expression was carried out exactly as previously described (3). Within each experiment, reactions were performed is triplicate and "no-template" controls were included. Averaged threshold cycle (CT) values for each reaction were normalized to $\beta$-actin values thus giving $\Delta \mathrm{CT}$ values. Alterations in gene expression were determined by comparison with the tissue value assigned as the calibrator, giving $\Delta \Delta C T$ values. Finally, relative gene expression was calculated using the formula $2^{-\Delta \Delta \mathrm{CT}}$.

tively between individual samples.

\subsection{Protein Expression Analysis}

Figure 1 shows representative inmunoblots of the seven enzymes that were studied. Levels of protein expression of the families 1, 2 and 3 of CYP enzymes showed very important inter-individual variations in skeletal muscle. CYP2W1 was only detected in the youngest patient (patient No. 1). CYP1B1 levels were clearly expressed in four samples (number 2 and 3 in girls, and number 3 and 6 in boys), reactivity with this protein coincides with gene expression shown. CYP1A1 and CYP1A2 were only detected in three female samples (number 2, 7 and 8), whereas in male, protein CYP1A1 was detected only in sample number 5. CYP2E1 protein was not detected in muscle samples. Expression of protein by members of family 3, CYP3A4 and CYP3A5, was detected in $61 \%$ $(11 / 18)$ and $22 \%(4 / 18)$ of the samples respectively. Marked differences were seen in the expression of CYP3A4, where most of the positive samples showed intensive protein expression.

\section{Discussion}

Little is known about CYP expression in human skeletal muscle, both adults and children. Nevertheless, the fact remains that there are considerable differences between adults and younger individuals in ontogenic gene expression and exposure to inducing xenobiotics and these may contribute to variations in drug metabolism in both groups [18]. Therefore, we examined the expression levels of CYP1A1, CYP1A2, CYP1B1, CYP2E1, CYP2W1, CYP3A4 and CYP3A5 in skeletal muscle of children and adolescents using qPCR and Western blotting. Our results indicate that several CYPs were expressed in skeletal muscle with marked inter-individual variation (Table 3). This variation in CYP expression can result from differential exposure to inducing xenobiotics.

In this study, members of CYP1 family: CYP1A1, CYP1A2, and CYP1B1, were detected in skeletal muscle with significant inter-individual variations in their expression. In all the samples, the gene expression for CYP1B1 was low however, with detectable protein levels. Conversely, the gene expression for CYP1A1 and their protein levels detected in 10 of the eighteen samples were markedly elevated in comparison with other isoforms evaluated. With respect to CYP1A2 that is considered as a "liver-specific" enzyme, gene expression was detected in only four samples of the skeletal muscle samples. These results are consistent with the result of a 

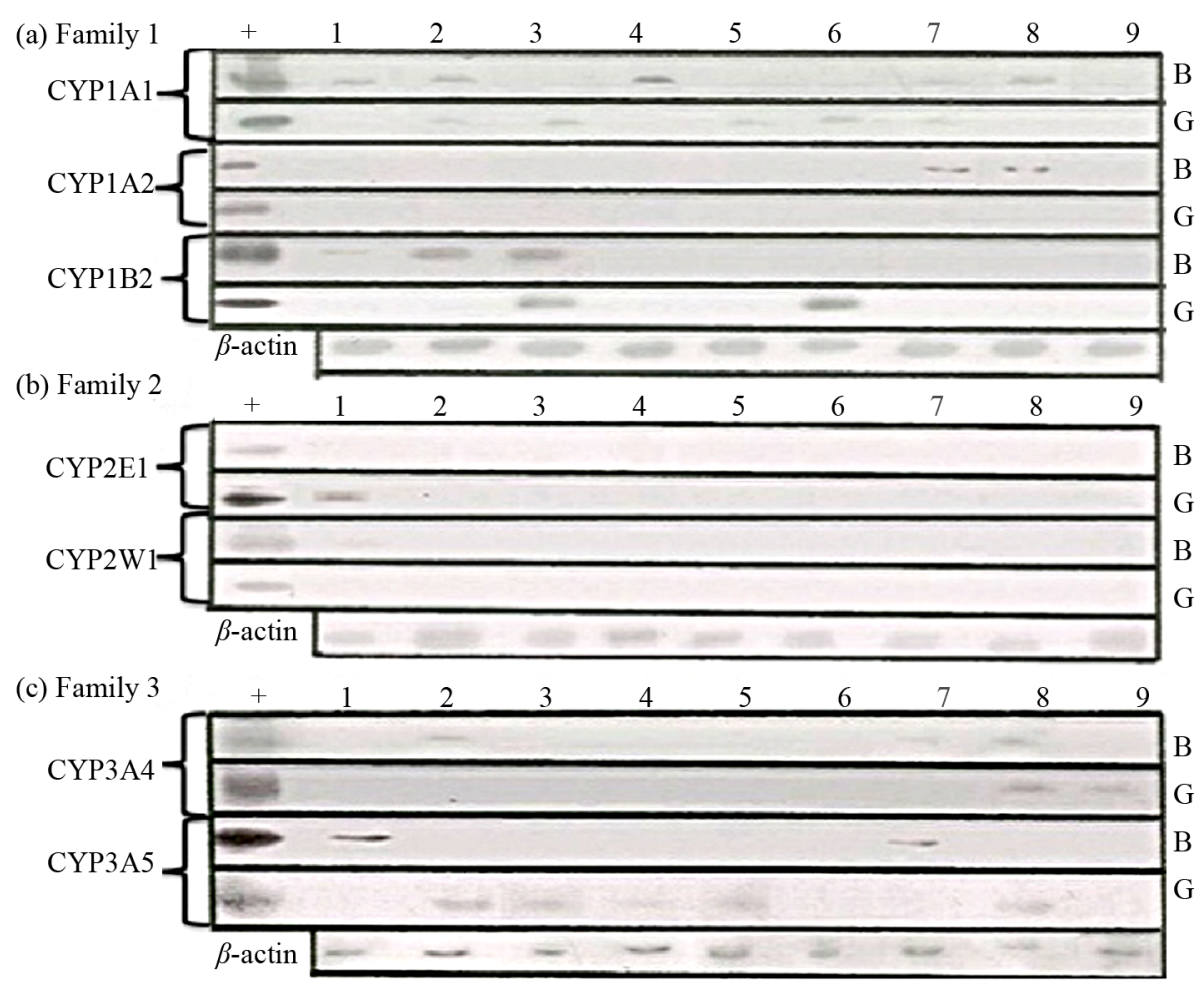

Figure 1. Expression of CYP proteins in human quadriceps skeletal muscle (40 $\mu \mathrm{g})$ from 18 patients: 9 girls [G] and 9 boys [B]. (a) Representative Western blots of CYP 1 family members: CYP1A1, CYP1A2 and CYP1B1; (b) Representative Western blots of CYP 2 family, members: CYP2E1 and CYP2W1; (c) Representative Western blots of CYP 3 family, members: CYP3A4 and CYP3A5. Patients were numbered by age (see Table 1). Supersomes are shown in lane "+" were used as positive controls for all blots.

previous study made to examine CYPs expression in a pool of different human tissues, including skeletal muscle [8]. In the later study, high levels of CYP1A1 mRNA and CYP1B1 were detected, while the level of CYP1A2 was slightly detectable.

The three members of CYP1 family are upper-regulated by aryl hydrocarbon receptor (AHR) when activated by ligands such as polycyclic aromatic hydrocarbons (PAHs), dioxin, $\beta$-naphthoflavone, and several dozens possible endogenous ligands $[19,20]$. CYP1A1 and CYP1B1 are specifically implicated in the activation of PAHs and heterocyclic amines [21,22]. Also, both CYP1A1 and CYP1B1 can metabolize estradiol to catecholestrogens [23]. This coupled with those reported by Aizawa et al. [24], who showed that skeletal muscle of rats expresses steroidogenic enzymes, suggesting that muscle tissue is highly active in the synthesis of steroid hormones. In addition, the most studied CYP1A1 substrates include various halogenated and non-halogenated PAHs procarcinogens. CYP1A1 metabolizes few drugs as acetaminophen to the toxic quinonaimine that could cause rhabdomyolysis [25,26].

The substrates of CYP1B1 include endogenous compounds such as steroids, retinoic acids, and melatonin. With respect to CYP1A2, our earlier observation cor- roborates with other reports where mRNA CYP1A2 was expressed in a number of tissues and cell lines [27].

In terms of CYP2E1 and CYP2W1 members of human CYP2 family, CYP2E1 mRNA was detected in all samples with less variation while mRNA CYP2W1 was found only in one of them. Bieche et al. [8] examined the expression of mRNA of several CYPs by adult skeletal muscle and found that CYP2E1 was expressed but CYP2W1 mRNA was not detectable. CYP2W1 is expressed in fetal stages of colon and over-expressed in a variety of human tumor cells such as lung, breast, liver, gastrointestinal tract, and ovarian cancer, but not in normal adult tissues [28]. The fact that CYP2W1 was detected only in the skeletal muscle of the youngest patient (patient No. 1) points to the possibility that such CYP could have been expressed in this tissue during prenatal stage and remained for the first few months after birth. However, we suggest that further studies be carried out to ascertain or not the expression of such CYP in prenatal period. Moreover, CYP2E1 enzyme has been studied extensively in adults due to its role in the metabolism of ethanol, and also as an activator of chemical carcinogens [29]. Most of the over 70 substrates demonstrated are small hydrophobic compounds, including a few drugs, such as paracetamol, chlorzoxazone, enflurane, and halo- 
thane [30,31]. It is also important to note that CYP2E1 induction in liver and skeletal muscle is associated with myotoxicity when acetaminophen is used, because CYP2E1 metabolizes acetaminophen to the toxic quinone imine [25]. In this study we detected CYP2E1 mRNAs in all skeletal muscle samples. However the very low amount of CYP2E1 mRNA may explain the lackage of its significance. Also the absence of CYPE1 protein in 17 samples evaluated, despite the detection of mRNA, may indicate posttranscriptional regulation of this isoform.

The human CYP3 family contains only one subfamily, the CYP3A, comprising of four genes: CYP3A4, CYP3A5, CYP3A7, and CYP3A43 [32]. This subfamily is especially important because Wacher et al. [33] showed that CYP3A is the primary CYP subfamily responsible for Phase I metabolism of over $50 \%$ of therapeutic agents administered to humans. Moreover, CYP3A contributes to the metabolism of numerous and endogenous molecules. Substrates of CYP3A include benzodiazepines, hydroxymethyl glutaryl-CoA reductase inhibitors, dihydropyridine calcium channel blockers, human immunodeficiency virus protease inhibitors, antiepileptics, chemotherapeutics, and immunosuppressants [34]. Inter-individual differences in the oral bioavailability and systemic clearance of CYP3A substrates can be attributed in large part to variable expression of CYP3A in the liver [35]. In our samples, CYP3A4 and CYP3A5 mRNAs were detected in 12 specimens even though CYP3A4 mRNA levels were much higher than CYP3A5. These results are consistent with Bieche and cols [8], which reported that CYP3A4 gene has high level of expression in pooled skeletal muscles of adults. Interestingly in our study, three samples corresponding to three adolescent patients (11, 15 and 16 years old) showed high levels of CYP3A4 with more than 20 times of gene expression and marked high protein levels. Similar results in inter-individual variation in hepatic CYP levels are known to occur [36]. Several endogenous parameters and environmental factors modulate the constitutive expression and induction of these enzymes. For example, carbamazepine and rifampin are known to induce CYP3A. It is unknown whether these exposures also induce these enzymes in skeletal muscle.

\section{Conclusions}

We have established for the first time the expression pattern of xenobiotic metabolizing CYPs in human skeletal muscle in children and adolescents. Our results confirm that skeletal muscle expresses various CYP enzymes suggesting that several xenobiotic chemicals to which humans are exposed could be metabolized in muscle cells. Also, in pharmacokinetics of many therapeutic drugs, there is potential involvement of muscle cells, pointing to the fact that the expression of CYPs in skeletal muscle may be involved in drug-dependent toxicity. This study provides insight into inter-individual variability in expression of CYP enzymes by muscle cells. The variations in mRNA and protein expression can be explained by differential exposure to inducing xenobiotics, which are specific of muscle tissues even when our cohort was drawn from younger patients that could be considered as a population less exposed to potent inducing agents such as cigarette smoke, alcohol, and drug consumption than adults. Alternatively, another possibility of this variability could be genetic polymorphisms in regulatory sequences or in coding regions of the genes, with potential consequences on the expression levels in tissues other than the skeletal muscle.

CYP1B1 and CYP2E1 genes are clearly expressed in skeletal muscle however, only the protein levels of CYP1B1 were detectable. CYP1A1 and CYP3A4 were the enzymes with major inter-individual differences in expression while CYP2W1 was not expressed in skeletal muscle samples with the exception of the 6-month old female patient.

In conclusion, the expression of CYPs in muscle cells in younger individuals may be an important factor in detoxification/activation processes because of the potential involvement of muscle in pharmacokinetics of many xenobiotics. In a broader sense, the involvement of CYP enzymes in pharmacological insults appears as a potential target for future pharmacogenetic studies.

\section{Acknowledgements}

This work was partially supported by CONACYTFondos Sectoriales Salud, Grant No. 86395.

\section{REFERENCES}

[1] J. Owczarek, M. Jasińska and D. Orszulak-Michalak, "Drug-Induced Myopathies. An Overview of the Possible Mechanisms," Pharmacology, Vol. 57, No. 1, 2005, pp. 23-34.

[2] T. Khazaeinia, A. A. Ramsey and Y. K. Tam, "The Effects of Exercise on the Pharmacokinetics of Drugs," Journal of Pharmacy and Pharmaceutical Sciences, Vol. 3, No. 3, 2000, pp. 292-302.

[3] J. R. Herman, "Drug Interaction and Statins," Canadian Medical Association Journal, Vol. 161, 1999, pp. 2811286.

[4] J. Warren, P. Blumbergs and P. Thompson, "Rhabdomyolysis: A Review," Muscle \& Nerve, Vol. 25, No. 3, 2002, pp. 332-347. doi:10.1002/mus. 10053

[5] Z. Argov, "Drug-Induced Myopathies," Current Opinion in Neurology, Vol. 13, No. 5, 2000, pp. 541-545. doi:10.1097/00019052-200010000-00006

[6] D. Nebert and T. Dalton, "The Role of Cytochrome P450 Enzymes in Endogenous Signalling Pathways and Envi ronmental Carcinogenesis," Nature Reviews Cancer, Vol. 


\section{6, 2006, pp. 947-960. doi:10.1038/nrc2015}

[7] B. Park, M. Pirmohamed and N. Kitteringham, "The Role of Cytochrome P450 Enzymes in Hepatic and Extrahepatic Human Drug Toxicity," Pharmacology \& Therapeutics, Vol. 68, No. 3, 1995, pp. 385-424. doi:10.1016/0163-7258(95)02013-6

[8] I. Biéche, C. Narjoz, T. Asselah, S. Vacher, P. Marcellin, R. Lidereau, P. Beaune and E. de Waziers, "Reverse Transcriptase-PCR Quantification of mRNA Levels from Cytochrome (CYP)1, CYP2 and CYP3 Families in 22 Different Human Tissues," Pharmacogenetics \& Genomics, Vol. 17, No. 9, 2007, pp. 731-742. doi:10.1097/FPC.0b013e32810f2e58

[9] P. Pavek and Z. Dvora, "Xenobiotic-Induced Transcriptional Regulation of Xenobiotic Metabolizing Enzymes of the Cytochrome P450 Superfamily in Human Extrahepatic Tissues," Current Drug Metabolism, Vol. 9, No. 2, 2008, pp. 129-143. doi:10.2174/138920008783571774

[10] S. Ellero, G. Chakhtoura, C. Barreau, S. Langoue, C. H. Benelli, L. Penicaud, P. Beaune and I. de Waziers, "Xenobiotic-Metabolizing Cytochromes P450 in Human White Adipose Tissue: Expression and Induction," Drug Metabolism and Disposition, Vol. 38, No. 4, 2010, pp. 679-686. doi:10.1124/dmd.109.029249

[11] S. C. Dogra, M. L. Whitelaw and B. K. May, "Transcriptional Activation of Cytochrome P450 Genes by Different Classes of Chemical Inducers," Clinical and Experimental Pharmacology and Physiology, Vol. 25, No. 1, 1998, pp. 1-9. doi:10.1111/j.1440-1681.1998.tb02135.x

[12] I. Bergheim, C. Bode and A. Parlesak, "Distribution of Cytochrome P450 2C, 2E1, 3A4, and 3A5 in Human Colon Mucosa," BMC Clinical Pharmacology, Vol. 5, 2005, p. 4.

[13] C. Tang, J. H. Lin and A. Y. Lu, "Metabolism-Based Drug-Drug Interactions: What Determines Individual Variability in Cytochrome P450 Induction?" Drug Metabolism and Disposition, Vol. 33, No. 5, 2005, pp. 603613. doi: $10.1124 / \mathrm{dmd} .104 .003236$

[14] X. Ding and L. Kaqminski, "Human Extrahepatic Cytochrome P450: Function in Xenobiotic Metabolism and Tissue-Selective Chemical Toxicity in the Respiratory and Gastrointestinal Tracts," Annual Review of Pharmacology and Toxicology, Vol. 43, 2003, pp. 149-173. doi:10.1146/annurev.pharmtox.43.100901.140251

[15] P. Rickham, "Human Experimentation. Code of Ethics of the World Medical Association," British Medical Journal, Vol. 2, 1964, p. 177. doi:10.1136/bmj.2.5402.177

[16] O. Lowry, N. Rosebrough, A. Farr and R. Randall, "Protein Measurement with the Folin Phonol Reagent," The Journal of Biological Chemistry, Vol. 193, No. 1, 1951, pp. 265-275.

[17] K. Livack and T. Schmittgen, "Analysis of Relative Gene Expression Data Using Real-Time Quantitative PCR and the 2 Delta Delta C (T)," Methods, Vol. 25, 2001, pp. 402-408.

[18] G. L. Kearns, S. M. Abdel-Rahman, S. W. Alander, D. L. Blowey, J. S. Leeder, et al., "Developmental Pharmacology-Drug Disposition, Action, and Therapy in Infants and Children," The New England Journal of Medicine,
Vol. 349, 2003, pp. 1157-1167. doi:10.1056/NEJMra035092

[19] D. Nebert, T. Dalton, A. Okey and F. Gonzalez, "Role of Aryl Hydrocarbon Receptor-Mediated Induction of the CYP1 Enzymes in Environmental Toxicity and Cancer," The Journal of Biological Chemistry, Vol. 279, 2004, pp. 23847-23850. doi:10.1074/jbc.R400004200

[20] D. Nebert and C. Karp, "Endogenous Functions of the Aryl Hydrocarbon Receptor (AHR): Intersection of Cytochrome P450 1 (CYP1)-Metabolized Eicosanoids and AHR Biology," The Journal of Biological Chemistry, Vol. 283, 2008, pp. 36061-36065. doi:10.1074/jbc.R800053200

[21] L. Nguyen and C. Bradfield, "The Search for Endogenous Activators of the Aryl Hydrocarbon Receptor," Chemical Research in Toxicology, Vol. 21, No. 1, 2008, pp. 102116. doi:10.1021/tx7001965

[22] T. Shimada, "Arylhydrocarbon Receptor-Dependent Induction of Liver and Lung Cytochromes P450 1A1, 1A2, and 1B1 by Polycyclic Aromatic Hydrocarbons and Polychlorinated Biphenyls in Genetically Engineered C57BL/6J Mice," Carcinogenesis, Vol. 23, No. 7, 2002, pp. 1199-1207. doi:10.1093/carcin/23.7.1199

[23] C. Martucci and J. Fishman, "P450 Enzymes of Estrogen Metabolism," Pharmacology \& Therapeutics, Vol. 57, No. 2-3, 1993, pp. 237-257. doi:10.1016/0163-7258(93)90057-K

[24] K. Aizawa, M. Iemitsu, T. Otsuki, S. Maeda, T. Miyauchi and N. Mesaki, "Sex Differences in Steroidogenesis in Skeletal Muscle Following a Single Bout of Exercise in Rats," Journal of Applied Physiology, Vol. 104, No. 1, 2008, pp. 67-74. doi:10.1152/japplphysiol.00558.2007

[25] C. Patten, P. Thomas, R. Guy, M. Lee, F. Gonzalez, F. Guengerich, et al., "Cytochrome P450 Enzymes Involved in Acetaminophen Activation by Rat and Human Liver Microsomes and Their Kinetics," Chemical Research in Toxicology, Vol. 6, No. 4, 1993, pp. 511-518. doi: $10.1021 / \mathrm{tx} 00034 \mathrm{a} 019$

[26] J. Raucy, J. Lasker, C. Lieber and M. Black, “Acetaminophen Activation by Human Liver Cytochromes P450IIE1 and P450IA2," Archives of Biochemistry and Biophysics, Vol. 271, No. 1, 1989, pp. 270-283. doi:10.1016/0003-9861(89)90278-6

[27] M. Iwanari, M. Nakajima, R. Kizu, K. Hayakawa and T. Yokoi, "Induction of CYP1A1, CYP1A2, and CYP1B1 mRNAs by Nitropolycyclic Aromatic Hydrocarbons in Various Human Tissue-Derived Cells: Chemical-, Cytochrome P450 Isoform-, and Cell-Specific Differences," Archives of Toxicology, Vol. 76, No. 5-6, 2002, pp. 287-298. doi:10.1007/s00204-002-0340-Z

[28] A. Gomez, M. Karlgren, D. Edler, M. Bernal, S. Mkrtchian, et al., "Expression of CYP2W1 in Colon Tumors: Regulation by Gene Methylation," Pharmacogenomics, Vol. 8, No. 10, 2007, pp. 1315-1325. doi: $10.2217 / 14622416.8 .10 .1315$

[29] J. Riggs, "Alcohol-Associated Rhabdomyolysis: Ethanol Induction of Cytochrome P450 May Potentiate Myotoxicity," Clinical Neuropharmacology, Vol. 21, No. 6, 1998, pp. 363-364. 
[30] C. Lieber, "Cytochrome P-4502E1: Its Physiological and Pathological Role," Physiological Reviews, Vol. 77, No. 2, 1997, pp. 517-544.

[31] M. J. J. Ronis, K. O. Lindros and M. Ingelman-Sundberg, "The CYP2E Subfamily," In: C. Ioannides and D. V. Parke, Eds., Cytochromes P450: Metabolic and Toxicological Aspects, CRC Press, Boca Raton, 1996, pp. 211239.

[32] D. R. Nelson, "Cytochrome P450 and the Individuality of Species," Archives of Biochemistry and Biophysics, Vol. 369, No. 1, 1999, pp. 1-10. doi:10.1006/abbi.1999.1352

[33] V. Wacher, C. Wu and L. Benet, "Overlapping Substrate Specificities and Tissue Distribution of Cytochrome P450 3A and P-Glycoprotein: Implications for Drug Delivery and Activity in Cancer Chemotherapy," Oncology \& Radiotherapy, Vol. 13, No. 3, 1995, pp. 129-134. doi:10.1002/mc.2940130302
[34] P. Guengerich, "Cytochrome P450 3A4: Regulation and Role in Drug Metabolism," Annual Review of Pharmacology and Toxicology, Vol. 39, 1999, pp. 1-17. doi:10.1146/annurev.pharmtox.39.1.1

[35] K. Thummel, D. Shen, T. Podoll, K. Kunze, W. Trager, et al., "Use of Midazolam as a Human Cytochrome P450 3A Probe: II. Characterization of Inter- and Intraindividual Hepatic CYP3A Variability after Liver Transplantation," Journal of Pharmacology and Experimental Therapeutics, Vol. 271, No. 1, 1994, pp. 557-566.

[36] L. M. Forrester, C. J. Henderson, M. J.Glancey, D. J. Back, B. K. Park, S. E. Ball, N. R. Kitteringham, A. W. McLaren, J. S. Miles, P. Skett, et al., "Relative Expression of Cytochrome P450 Isoenzymes in Human Liver and Association with the Metabolism of Drugs and Xenobiotics," Biochemical Journal, Vol. 281, 1992, pp. 359-368. 